\title{
Mathematical modelling of heat accumulator for thermal preparation system of road-building machinery
}

\author{
Konev Vitaliy Valerievich \\ Industrial University of Tyumen, IUT \\ Tyumen, Russia \\ konev2210@yandex.ru \\ Krut Oksana Borisovna \\ Industrial University of Tyumen, IUT \\ Tyumen, Russia
}

\author{
Polovnikov Egor Viktorovich \\ Industrial University of Tyumen, IUT \\ Tyumen, Russia \\ Dolzhikova Lyudmila Vasilievna \\ Industrial University of Tyumen, IUT \\ Tyumen, Russia
}

\author{
Rood' Elena Evgenievna \\ Southern University (IMBL), SU \\ Rostov-on-Don, Russia
}

\begin{abstract}
In the conditions of autonomous functioning of special equipment, there is a need to use its internal sources. This can be accomplished using a heat recovery system of the internal combustion engine. For this purpose, the authors suggest a heat accumulator. The mathematical modelling of the thermal state of the heat accumulator in the cooling stage is done. The main factors affecting the cooling time of the thermal accumulator are the thickness of the insulation of the heat accumulator, the mass of coolant, coolant temperature, air temperature, wind speed. The authors also developed a mathematical model of the cooling process of the heat accumulator in a general way. It is presented in graphical form, which makes it easier to determine the time of cooling the heat accumulator in the process of its designing. For automatic calculation, an algorithm has been developed and implemented in the program to determine the dimensionless temperature and criterion Bio.
\end{abstract}

Keywords -operation, modeling of the thermal accumulator, thermal preparation, heat transfer, heat recovery system, low negative temperatures.

\section{INTRODUCTION}

On the construction sites in the North and Extreme North of Russia, a large park of road-building machinery (RBM) operates. In the absence of a roads' network, waterlogged terrain, strong flooding of soils with positive temperatures of the air, there are difficulties with the delivery of equipment to the construction sites [1]. Therefore, the construction work is carried out in the wintertime.

In the north of the Tyumen region, there are also many RBM. Their quantity has had a tendency lately to sharply increase due to the development of new gas fields in Yamal, large scale road construction and the laying out of new gas pipelines in Eastern Siberia. At the same time, the majority of this fleet consists of general construction machinery, i.e. they are not designed for arctic service. It is especially visibly confirmed in connection with the RBM market expansion of the comparatively cheap equipment produced in South East Asia and China. These producers prefer to produce all-service equipment, disregarding concerns, related to adaptation to the local conditions on the organizations that use this machinery.

The work of RBM is carried out in condition of low temperatures, wind [2]. These machines are operated autonomously - away from fixed bases. This eliminates the storing of cars in garages and the use of external sources of thermal energy. Therefore, there are difficulties with the engine start (internal combustion engine (ICE), the hydraulic actuator, the section of RBM) at the beginning of the work shift, after between shifts parking in open area [3 - 5]. To ensure the efficiency of the machines, different means of thermal preparation are used [6 - 8].

Application of already existing means of thermal preparation have proved to be ineffective. Some of them were not widely adopted because of the complexity of design or the unjustified high cost of installation, which also needs to be considered when introducing similar systems to a large number of already operating machinery. Based on all this, there is the need to create effective, compact, inexpensive in manufacture and installation systems that can autonomously warm the elements without an external source of heat or energy. This will greatly enhance the value of such development and is relevant, taking into account the fact that most of the work undertaken by these machines, is performed away from the point locations.

Taken into account the fact that, when the machine is working, all its units generate heat, which is dissipated into the surrounding area; there is the task of using this heat to heat preparation of the machine before it starts. One option of the thermal preparation is a heat recovery system that uses thermal accumulators (TA). The heat accumulated and stored in that 
TA is used for thermal preparation of car units after their between shifts parking [9-11].

\section{EVALUATION OF THE THERMAL STATE OF THE HEAT ACCUMULATOR}

The calculations of the thermal state of the ICE showed that in the surrounding air when RBM works, about $40 \%$ of thermal energy is lost with the coolant and up to $25 \%$ of heat is lost with exhaust gases of ICE (Fig. 1) $[10,11]$. This heat is proposed to be accumulated in TA while RBM is working. The authors evaluated the thermal state of the TA.

The quality of work of heat recovery systems depends primarily on the quality of the TA and its thermal capacity. Therefore, the authors considered the cooling process of TA after its filling with the cooling liquid (coolant) from the water cooling jacket of ICE [10].

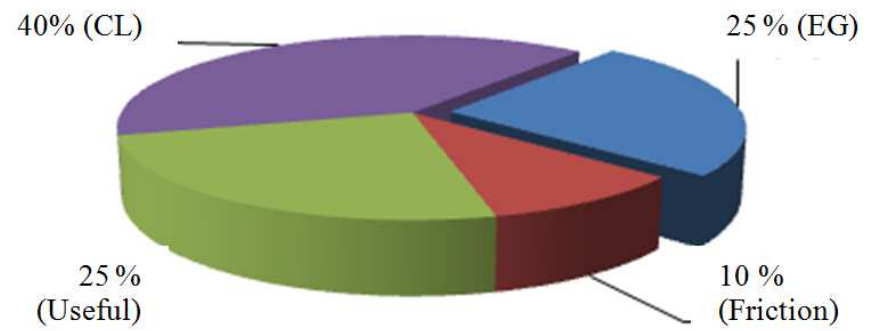

Fig. 1. Thermal balance of the internal combustion engine. EG - exhaust gases. CL - energy of cooling liquid. Friction. Useful energy

The design of TA is possible with several cameras. The schemes of the location of the cameras in the double-cameras heat accumulator are presented in Fig. 2. This allows one to obtain different heat capacities at the stage of storing heat.

The following factors affected the rate of cooling: the type of heat-retaining material, the type of insulation material, insulation thickness of TA, the surface area of cooling, the mass of coolant, coolant temperature, the temperature of the air, the wind speed $[7,9,10,11]$. A large number of factors complicate the research process of cooling TA. It is not necessary to consider all the factors because of possible irrelevant or insignificant factors influencing the thermal process of TA. Therefore, the task was to establish the relationship between these factors and the cooling time of TA.

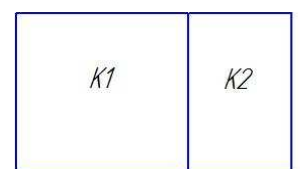

a)

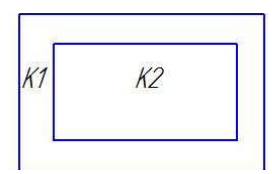

b)

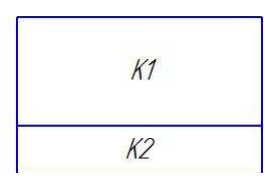

c)
Fig. 2. The schemes of the location of the cameras in the double-chamber heat accumulator: a) the first chamber (K1) has a common wall with the second chamber (K2); b) the second chamber is inside the first one; c) the second chamber is under the first chamber
In the process of TA cooling with increasing time $d \tau$, the temperature difference will tend to zero to achieve thermal equilibrium with the surrounding air. The whole TA cooling process can be divided into three modes: irregular, regular and stationary [12]. In this case, the presence of the irregular mode is indicated by the fact that thermal quality of TA materials is different, and, respectively, at initial time $\tau=0$, temperature differences vary. For the TA cooling process, the authors neglected the irregular regime of cooling since it is short in relation to the entire duration of the cooling process. This was confirmed by preliminary experimental studies. Then, considering all TA elements, taking initial temperature $t_{\text {initial }}$, when the cooling starts in the environment with temperature $t_{\text {air }}$, the authors can consider the process of cooling as a regular one. This allows one to simplify the mathematical model, since all changes in the system may be equal to each other and may be characterized as excessive temperature $v=t-t_{\text {air }}$, where $t$ is the current temperature of TA. It is obvious that in the initial moment, excessive temperature is $v_{0}=t_{\text {initial }}-t_{\text {air }}$. The third cooling mode is stationary when the temperatures at all TA points become equal to the temperature of the air. This mode is excluded from consideration, because TA cooling at negative temperatures below the critical temperature will lead to parametric failure of TA.

The speed of propagation of isothermal surface in the bodies depends on the ratio of the bodies' surface to their volume. The study of the processes of bodies' cooling indicates that the greater the ratio of body surface to its volume, the greater the rate of temperature differences [12]. This temperature deference tends to increase the time of cooling: a cube, a cylinder, a sphere. From the above mentioned information, it follows that the shape of the sphere is the most effective form of TA, but because of the difficulties of manufacturing, installation and setting the profitability of TA, it will decrease. Therefore, the authors have selected cylinder as the TA shape. From the conducted researches, it is determined that the cylinder must be the correct form, i.e. the cylinder diameter should be equal to its height.

\section{MATHEMATICAL MODELLING OF THE THERMAL STATE OF THE THERMAL ACCUMULATOR}

The efficiency of TA is determined by its size, as the greater the TA size, the less the relative loss of heat is. The dimensions of TA depend on the length of time of heat preservation.

In determining the size of TA, it is important to calculate the thickness of the thermal insulation since the surface area of thermal insulation will determine the cooling time. There may be a situation when the greater thicknesses of insulation TA will cool faster than that with a smaller thickness of insulation [12]. The dependence of heat losses on the thickness of the insulation, imposed on the cylindrical wall, is presented in Fig. 3. 


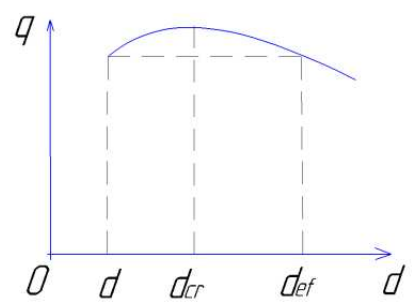

Fig. 3. The dependence of heat losses on the thickness of the insulation, applied to the cylindrical wall: $q$ - thermal losses, $d_{c r}$ - the critical diameter, $d_{e f}$ - the effective diameter

The value of the outside diameter, corresponding to the minimum total thermal resistance of heat transfer, is called the critical diameter and is symbolled by $d_{c r}$. It is calculated by the formula:

$$
d_{c r}=2 \lambda / \alpha
$$

When $d<d_{c r}$ with the increasing of $d$, the total thermal resistance of the heat transfer decreases because the increase of the external surface has a greater influence on the thermal resistance than the increase of wall thickness.

When $d<d_{c r}$ with increasing $d$, thermal resistance of heat transfer increases, which indicates a dominant influence of the wall thickness.

The above-mentioned concerns must be taken into account when selecting thermal insulation to cover TA.

The differential equation of heat conductivity without an internal heat source is calculated by the formula:

$$
d t / d \tau=a\left(d^{2} t / d x^{2}+d^{2} t / d y^{2}+d^{2} t / d z^{2}\right) .
$$

The uniqueness conditions are given in the form of:

- physical parameters $(\lambda, c, p)$;

- dimensions of TA $(l ; \delta)$;

-TA temperature in the initial time $\tau=0, t=t_{0}=$ $f(x, y, z)$.

The boundary conditions in this case can be specified as boundary conditions of the third kind:

$$
(d t / d n)_{n=0}=-\alpha / \lambda\left(t_{n=0}-t_{\text {coolant }}\right) .
$$

The differential equation of heat conductivity (2) together with the conditions of uniqueness gives a complete mathematical formulation of the considered problem. Its solving is in finding the function:

$$
t=f\left(x, y, z, \tau, \alpha, \lambda, a, t_{0}, t_{\text {coolant }}, l\right) .
$$

This function (4) must correspond to equation (2) and to the condition of uniqueness. TA is insulated. The authors consider thermal insulation of TA as the plate of thickness $\delta$. The cooling occurs at a constant ambient temperature of $t_{\text {air }}=$ const . The authors assume that the heat removal is carried out with the same heat transfer coefficient ( $\alpha=$ const) over the entire period of time. The readout of the temperature of the plate for any time starts from the ambient temperature, i.e., $t-t_{\text {air }}=v$. The authors will substitute excess temperature $v$ in differential equation (2) and in the boundary conditions. The temperature along axes $y$ and $z$ does not change, so $d v / d y=0$ and $d v / d z=0$, and differential equation (2) takes the following form:

$$
d v / d \tau=a\left(d^{2} v / d x^{2}\right)
$$

These are initial conditions,

$$
\text { when } \tau=0, v=v_{0}=t_{0}-t_{\text {air }}
$$

The beginning of coordinates in contrast to the classical formulation of the problem is convenient to put on the plate surface, which is in contact with the coolant. In this case, the boundary conditions for the plate are:

a) on the surface of the plate when $x=0$,

$$
(d v / d n)_{n=0}=0
$$

b) on the surface of the plate when $x=\delta$,

$$
(d v / d n)_{x=0}=-\alpha / \lambda v_{x}=\delta
$$

Differential equation (5) together with initial (6) and boundary (7), (8) conditions clearly generates the given task. The solution of differential equation (5), taking into account the initial and boundary conditions, gives the desired dependence on the temperature distribution in a flat plate. With a given $B i$, the dimensionless temperature depends linearly on time, which allows solving the problem graphically.

The dimensionless temperature is calculated from the dependence:

$$
\theta=\left(t_{\text {coolant }}^{\text {current }}-t_{\text {air }}\right) /\left(t_{0}-t_{\text {air }}\right)
$$

where $t_{\text {coolant }}^{\text {current }}$ - coolant temperature $\left({ }^{\circ} \mathrm{C}\right)$ (current) after time $\tau ; t_{0}$ - the initial temperature of coolant, ${ }^{\circ} \mathrm{C} ; t_{\text {air }}-$ the ambient air temperature, ${ }^{\circ} \mathrm{C}$.

When the plate becomes cool, each subsequent moment of time will have its own curve, which monotonically decreases to the surfaces of the plate. Thus, for any moment of time, the tangent to the curve at point $X=1$ passes through guide point A, located at distance $X_{0}$ from the surface of the plate (Fig. 4).

$$
X_{0}=l / B i
$$

From equation (10), it follows that the distance of point $\mathrm{A}$ from the surface is determined by the given conditions of uniqueness, which are valid for any point in time. Hence, the tangents to all temperature curves at the point of intersection with the surface of the plate with the constant boundary conditions will always pass through point A. This property of the temperature curves allows determining the character of temperature change in a body at a given $\mathrm{Bi}$. 


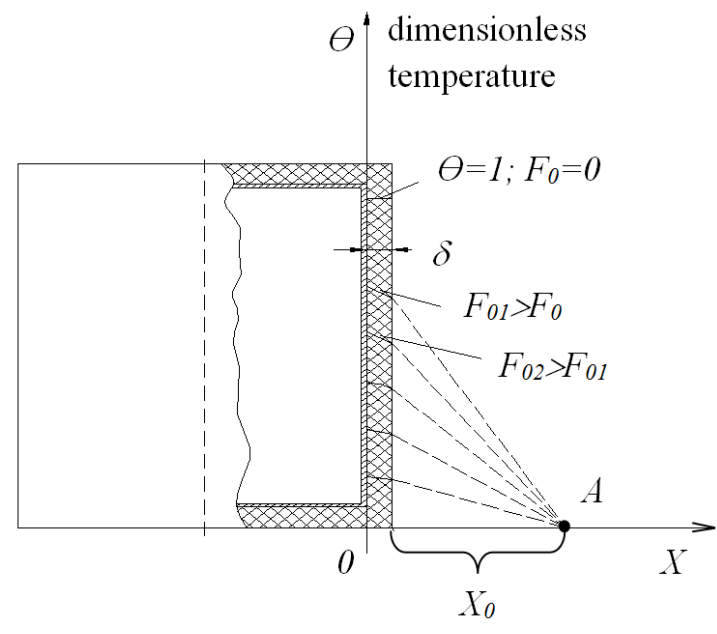

Fig. 4. Modifying the temperature field in the insulation layer: $\delta$ - insulation thickness, $\left(F_{0}-\right.$ Fourier's criterion, $\theta$-dimensionless temperature

In the case under consideration, criterion $\mathrm{Bi}$ is in the range: $0.1 \leq \mathrm{Bi}<100$. The temperature curves for any point of time will look as it is shown in (Fig. 4). In this case, both internal and external thermal resistance defines the intensity of the cooling process.

The temperature equalization in TA is more intense than the heat removal from the surface, i.e. a cooling process of TA is determined by the intensity of heat transfer on the surface of the insulation. This allows considering TA as the «black box», where the result of thermal processes is an output parameter, the temperature at the boundary of the outer insulation layer and the outside air, which is completely and uniquely determined by the processes inside TA. The introduction of this parameter allows one to simplify the task and to increase the accuracy of calculations, because it is possible to dispose the discrete variables and to proceed to the consideration of the cooling process in TA dynamics with arbitrarily small periods of cooling time $d \tau$. Analytical description of the process of heat conduction involves the differential equation and the uniqueness conditions.

Setting the temperature on the surface of TA, the authors obtained lines $B i$ (Fig. 5). The sequence of the graphing

$\theta=f\left(B i, F_{0}\right)$ is the following:

$$
\theta=\left(t_{\text {coolant }}^{\text {current }}-t_{\text {air }}\right) /\left(t_{0}-t_{\text {air }}\right) .
$$

1. The calculating of $\mathrm{Gr}$ - in this case, the temperature pressure was calculated from the experiments.

2. The calculating of $N u$, including the wind.

3. The calculating of $\alpha$.

4. Checking condition $d>d_{c r}$.

5. The calculation of $\mathrm{Bi}$.

6. The calculation of $F_{0}$, temperature conductivity - $a$.

7. The calculation of $\theta$.

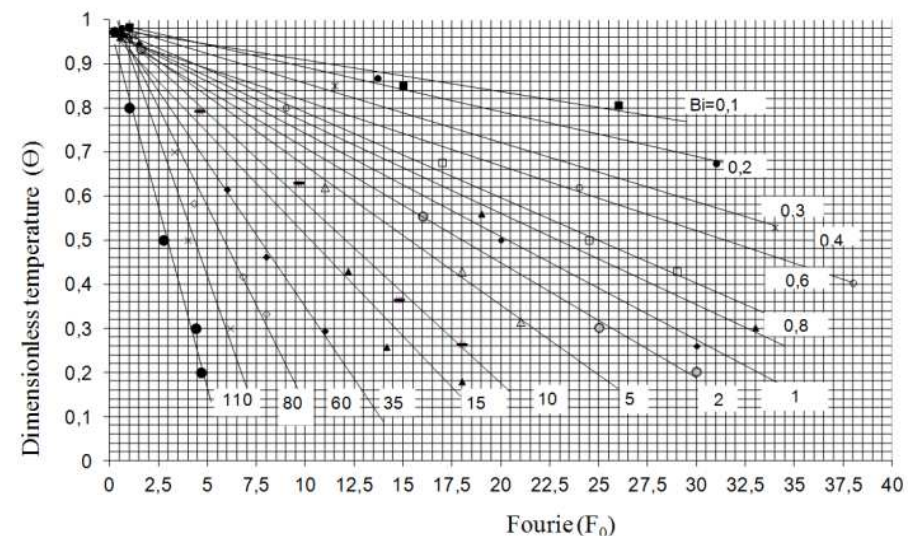

Fig. 5. The dependence of the dimensionless temperature $(\theta)$ on criterion Bio $(B i)$ and Fourier $\left(F_{0}\right)$ for the surface of TA

For each point of time, there are corresponding $F_{0}$ and $\theta$, and for each TA, the authors defined points with the same $\alpha$, which allows one to determine $B i$. The obtained results are graphed where the $\mathrm{X}$-axis $-F_{0}$ and the $\mathrm{Y}$-axis $-\theta$.

On the built graph of $\theta=f\left(B i ; F_{0}\right)$ (Fig. 5), it is very easy at the design stage to determine the cooling time of TA and its temperature in a subsequent point in time at a given temperature of ambient air when the initial surface temperature of TA and the temperature of the coolant are calculated. For this purpose, it is necessary to determine desired $B i$ at the intersection of calculated $F_{0}$ and $\theta$. This $B i$ (a line) is the line that describes the projected TA.

The calculations showed that under initial conditions: cylinder volume is $0.03 \mathrm{~m}^{3}$; thermal insulation is foam with thickness $\delta=0.1 \mathrm{~m}$; the temperature is $-40{ }^{\circ} \mathrm{C}$; the initial temperature of TA is $85^{\circ} \mathrm{C}$; the lowering of the coolant temperature in TA is by $\left(10-15^{\circ} \mathrm{C}\right)-B i=16.39$, which corresponds to the time of heat storage in TA 17.3 hours.

If the authors use the known dependencies to determine the surface area of the cylinder in which $D=H$, the average surface area of a cylindrical TA can be determined by the formula:

$$
S=5.529 V^{0.6667},
$$

where, $V$ is the volume of a cylindrical TA, $m^{3}$. The dependence of the cylinder area on TA volume is presented in Fig. 6.

In formula (12), the value of $V$ is determined from the volume of coolant $V_{\text {coolant }}$ located in the TA. It is necessary to take into account air gap $V=V_{\text {coolant }}\left(m^{3}\right)$, when $\rho_{\text {coolant }} V_{\text {coolant }}=M_{\text {coolant }}(\mathrm{kg}), \rho\left(\mathrm{kg} / \mathrm{m}^{3}\right)$. As a result, instead of formula (12), there is:

$$
S=5.529\left(M_{\text {coolant }} / \rho_{\text {coolant }}\right)^{0.6667}
$$

From constructive reasons, the authors take the thickness of the TA $\delta=0,002 \mathrm{~m}$. Then taking into account (13), the authors determine the volume of metal of the TA. In line with this and considering that mass and volume are connected $(M=\rho V)$, one obtains: 


$$
M_{\text {met }}=7800 \mathrm{~S} \delta_{\text {met }} \simeq 86,25\left(M_{\text {coolant }} / \rho_{\text {coolant }}\right)^{0.6667}
$$

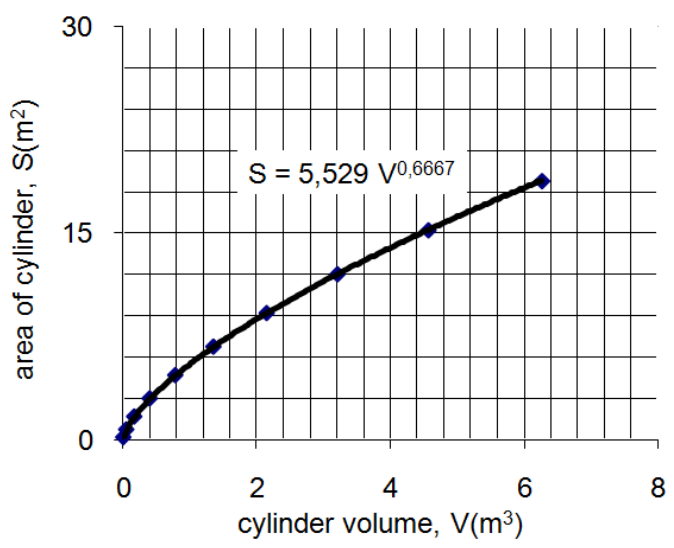

Fig. 6. The dependence of the area of TA cylinder on its volume

In addition to the basic elements, the hull structure of TA includes units of fastening, cover, pipe components, neck, etc., that the authors take into account by introducing coefficient 1.25 in calculation formula (14). As a result, finally there is:

$$
M_{m e t} \cong 107,8\left(M_{\text {coolant }} / \rho_{\text {coolant }}\right)^{0.6667}
$$

Formula (15) is a general expression for determining the mass of metal for thermal accumulators of various sizes.

The general formula for determining the mass of insulation regardless of the type of thermal insulation material is determined. To do this, the authors consider that its volume is the difference between the volumes of cylinders $V_{1}$ and $V_{2}$ with radii $R+\delta$ and $R$, then:

$$
V_{2}=2 \pi(R+\delta)^{3}
$$

by simple calculations, the authors assume that $R=3 V / S$, and since $V=M / \rho$, then from (16), one obtains:

$$
\begin{gathered}
V_{2}=2 \pi\left(\frac{3\left(\frac{M_{\text {coolant }}}{\rho_{\text {coolant }}}\right)^{0,333}}{5,529}+\delta\right)^{3}, \\
V_{\text {in }}=V_{2}-V_{1},
\end{gathered}
$$

according to (17) and (18), there is:

$$
V_{\text {in }}=2 \pi\left(0,54 \times\left(\frac{M_{\text {coolant }}}{\rho_{\text {coolant }}}\right)^{0,333}+\delta\right)^{3}-\frac{M_{\text {coolant }}}{\rho_{\text {coolant }}},
$$

Formula (19) is the generalized expression to determine the volume of insulation $\left(V_{i n}\right)$ for various TA.

\section{PRACTICAL IMPLEMENTATION OF THEORETICAL STUDIES}

The time values of TA cooling with different thermal insulation material and its thickness can be also determined using the developed program «Time». The algorithm of the developed program is the following:

1. The parameters of TA are: height $l,(m): 0.4,0.5,0.6$, 0.7 ; thermal conductivity of thermal insulation material $\lambda,(W /$ $\left.m^{\circ} \mathrm{C}\right): 0.116,0.066,0.037,0.047$; heat capacity of the material $\mathrm{C}\left(\mathrm{kJ} / \mathrm{kg} \cdot{ }^{\circ} \mathrm{C}\right)$, respectively, $0.82,0.92,0.67,0.75$; density of insulation $\rho,\left(\mathrm{kg} / \mathrm{m}^{3}\right)$, respectively, 770, 250, 200, 250; diameter of TA $d,(m): 0.4 \mathrm{~m}, 0.5 \mathrm{~m}, 0.6 \mathrm{~m}, 0.7 \mathrm{~m}$; thickness of the insulation $\delta(\mathrm{m}): 0.025,0.05,0.1$; surface temperature of insulation $\left({ }^{\circ} \mathrm{C}\right):+3,+6,+9 ; \beta-$ the coefficient of thermal expansion of coolant $V t: 1 / 263,1 / 243 ; 1 / 233 K) ; t_{0}$ - the initial temperature of $\mathrm{TA},\left({ }^{\circ} \mathrm{C}\right): 85,90,95 ; t_{\text {conlant }}^{\text {current }}$ is the first current temperature of the coolant $\left({ }^{\circ} \mathrm{C}\right): 70,75,80$; the cooling time relative to the current temperature of coolant $\tau$ (hour): $0.2,0.6,0.1,1.3$.

2. The environmental parameters are: air temperature $t$ $\cdot\left({ }^{\circ} \mathrm{C}\right):-10,-30,-40 ;$ speed of motion of the moving environment (wind speed) $-v(\mathrm{~m} / \mathrm{s}): 10,15 ; \mathrm{v},\left(\mathrm{m}^{2} / \mathrm{s}\right)$ - the kinematic viscosity coefficient of air $13 \cdot 10^{-6} ; \mathrm{g},\left(\mathrm{m} / \mathrm{s}^{2}\right)$ the acceleration of free falling 9.8; $\operatorname{Pr}=0.7$.

If $v=0$, then:

3. Gr is calculated according to the formula:

$G r=g \beta l^{3} \cdot \Delta T / v^{2}$; the authors calculate $G r \cdot P r$.

4. $\mathrm{Nu}$ is determined:

- provided that $10^{3}<\mathrm{Gr} \cdot \operatorname{Pr}<10^{9}$, corresponding to laminar mode

$N u=0.76 \cdot(G r \cdot P r)^{0.25} \cdot\left(P r_{\text {coolant }} / P r_{\text {insulation }}\right)^{0.25}$;

- provided that $G r \cdot \operatorname{Pr}>10^{9}$, corresponding to turbulent mode $N u=0.15 \cdot(G r \cdot P r)^{0.33} \cdot\left(P r_{\text {coolant }} / P r_{\text {insulation }}\right)^{0.25}$.

If $v>0$, then (with the wind) $R e=v l / v$ :

- provided that $R e<2000$ (laminar flow mode in the absence of free convection)

$N u=0.15 \cdot R e^{0.33} \cdot \operatorname{Pr}^{0.43} \cdot\left(P r_{\text {coolant }} / \operatorname{Pr}_{\text {insulation }}\right)^{0.25}$;

- provided that $R e<2000$ (laminar flow mode in the presence of free convection)

$N u=0.15 \cdot R e^{0.33} \cdot P^{0.43} \cdot G r^{0.1}$.

$\left(\mathrm{Pr}_{\text {coolant }} / \mathrm{Pr}_{\text {insulation }}\right)^{0.25}$;

- provided that $R e>10000$ (turbulent flow mode)

$N u=0.021 \cdot R e^{0.80} \cdot P^{0.43} \cdot\left(P r_{\text {coolant }} / P r_{\text {insulation }}\right)^{0.25}$.

5. $\alpha$ is calculated from expression $N u=\alpha l / \lambda$

6. According to formula $d_{c r}=2 \lambda / \alpha$, the authors verify condition $d>d_{c r}$. In other cases, all the input data are reviewed (heat insulation and thickness).

7. $B i$ is calculated according to formula $B i=\alpha \delta / \lambda$.

8. $\theta$ is calculated according to formula

$\theta=\left(t_{\text {coolant }}^{\text {current }}-t_{\text {air }}\right) /\left(t_{0}^{\text {initial }}-t_{\text {air }}\right)$.

9. The temperature conductivity is determined by formula $a=\lambda /\left(c_{\mathrm{p}} \rho\right)$.

10. According to built graph $\theta=f\left(B i ; F_{0}\right)$ (Fig. 4) at the intersection of calculated dimensionless temperature $\theta$ and 
criterion Bio ( $\mathrm{Bi}$, the authors defined $F_{0}$. According to formula $F_{0}=a \tau / \delta^{2}$, the authors calculated cooling time $\tau$.

The mathematical model of the cooling process of TA in a general view is presented in the graphic form, which simplifies the determination of the cooling time of TA in the process of its design. To determine $\theta$ and $B i$. The authors developed a calculation algorithm, implemented in the computer program «Time» (TABLE I).

The table presents the implementation of the calculation in the program «Time» by determining the TA cooling time.

TABLE I The calculation in the program «Time» to determine the time of TA cooling

\begin{tabular}{|c|c|c|}
\hline \multicolumn{3}{|c|}{ Initial Data } \\
\hline Value & Symbol & Description \\
\hline 0.5 & $l$ & Height, $m$ \\
\hline 0.066 & $a_{\text {insulation }}$ & $\begin{array}{l}\text { Thermal conductivity } \\
\text { Thermal insulation } \mathrm{W} /\left(\mathrm{m}^{\circ} \mathrm{C}\right)\end{array}$ \\
\hline 0.024 & $a_{\text {air }}$ & $\begin{array}{l}\text { Thermal conductivity of air, } \\
\mathrm{W} /\left(\mathrm{m} ;{ }^{\circ} \mathrm{C}\right)\end{array}$ \\
\hline 920 & $c$ & $\begin{array}{l}\text { Heat capacity of material } \\
\mathrm{J} /\left(\mathrm{kg} \cdot{ }^{\circ} \mathrm{C}\right)\end{array}$ \\
\hline 250 & $r$ & $\begin{array}{l}\text { Density of insulation } \\
\mathrm{kg} / \mathrm{m}^{3}\end{array}$ \\
\hline 0.5 & $\mathrm{~d}$ & Diameter of TA, m \\
\hline 0.1 & $\delta$ & $\begin{array}{l}\text { Thickness of thermal insulation, } \\
\mathrm{m}\end{array}$ \\
\hline 6 & $t_{\text {insulation }}$ & $\begin{array}{l}\text { The surface temperature of } \\
\text { insulation, }{ }^{\circ} \mathrm{C}\end{array}$ \\
\hline $\begin{array}{l}3.802 \mathrm{E}- \\
03\end{array}$ & $b$ & $\begin{array}{l}\text { Coefficient of thermal expansion } \\
\text { of the coolant, } 1 / \mathrm{K}\end{array}$ \\
\hline 85 & $t_{0}$ & The initial temperature of $\mathrm{TA},{ }^{\circ} \mathrm{C}$ \\
\hline 75 & $t_{\text {coolant }}^{\text {current }}$ & $\begin{array}{l}\text { The current temperature of the } \\
\text { coolant, }{ }^{\circ} \mathrm{C}\end{array}$ \\
\hline 23 & $\tau$ & $\begin{array}{l}\text { Cooling time relative to the } \\
\text { current temperature of the } \\
\text { coolant, } \mathrm{h}\end{array}$ \\
\hline-25 & $t$ & The ambient air temperature, ${ }^{\circ} \mathrm{C}$ \\
\hline 10 & $v$ & Wind speed, $\mathrm{m} / \mathrm{s}$ \\
\hline $\begin{array}{l}1.300 \mathrm{E}- \\
05\end{array}$ & $v$ & $\begin{array}{lll}\text { The kinematic } & \text { viscosity } \\
\text { coefficient of air, } \mathrm{m}^{2} / \mathrm{s} & \end{array}$ \\
\hline 9.8 & $g$ & Free falling acceleration, $\mathrm{m} / \mathrm{s}^{2}$ \\
\hline 0.7 & $\operatorname{Pr}$ & Prandtl number for air \\
\hline 1 & $\left(P r_{\text {coolant }} / P r_{\text {insulation }}\right)^{0.25}$ & \\
\hline \multicolumn{3}{|c|}{ Calculations Characteristics } \\
\hline- & $G r$ & $\begin{array}{l}\text { The Grashof number (in the } \\
\text { absence of wind } V=0 \text { ) }\end{array}$ \\
\hline- & $\mathrm{Gr} \cdot \mathrm{Pr}$ & \\
\hline 384615.4 & $\operatorname{Re}$ & $\begin{array}{l}\text { The Reynolds number (in the } \\
\text { presence of wind } V>0 \text { ) }\end{array}$ \\
\hline \multicolumn{3}{|c|}{ Program to Define Nusselt Number } \\
\hline 529.2158 & $N u$ & $\begin{array}{l}\text { Turbulent flow mode in the } \\
\text { presence of wind }\end{array}$ \\
\hline \multicolumn{3}{|c|}{ Checking Condition $d>d_{c r}$} \\
\hline 25.40236 & $\alpha$ & Heat transfer coefficient \\
\hline 0.005196 & $d_{c r}$ & $\begin{array}{l}\text { The critical diameter of thermal } \\
\text { insulation }\end{array}$ \\
\hline $\begin{array}{l}\text { The } \\
\text { condition } \\
\text { is true }\end{array}$ & & Checking result \\
\hline \multicolumn{3}{|c|}{ Definition $B i$, teta, a } \\
\hline 38.48842 & $B i$ & Number Bio \\
\hline 0.909091 & $\theta$ & Dimensionless temperature \\
\hline $2.87 \mathrm{E}-07$ & $a$ & Temperature conductivity \\
\hline
\end{tabular}

The mathematical model of the cooling process of TA in general view is presented in the graphic form, which simplifies the determination of the cooling time of TA in the process of its design. To determine dimensionless temperature $\theta$ and criterion Bio $(\mathrm{Bi})$, the authors developed a calculation algorithm, implemented in a computer program.

\section{References}

[1] Sh.M. Merdanov, Mechanized complexes for the building of temporary winter roads: scientific publication, TSOGU, Tyumen: TSOGU, 2013.

[2] N. S. Zakharov, "The relationship between climatic factors", Scientifictechnical Vestnik of the Volga region, No 1, pp. 26 - 29, 2014.

[3] R. Lakhov, "Operation of heavy equipment at low temperatures", Basic Funds, No. 11, 2009.

[4] V. A. Vasilchenko, "Peculiarities of operation of mining machines with hydraulic motors at low temperatures", Mining Industry, No. 2, 2006.

[5] A set of rules for design and construction (SR 12-104-2002) "Mechanization of building. Operation of building machines during the winter period" (approved by resolution of the State Committee for Construction of the Russian Federation on the $27^{\text {th }}$ of February 2003, No. 25).

[6] S.V. Kaverzin, Performance hydraulic drive at low temperatures, Atlanta: Publishing House of Krasnoyarsk University, 1986.

[7] N.N. Karnaukhov, Adaptation to the conditions of construction machinery in the Russian North and Siberiaб Moscow: Nedra, 1994.

[8] V.V. Konev, Sh.M. Merdanov, M.M. Karnaukhov, D.M. Borodin, "Thermal preparation of the trailbuilder fluid drive" WIT Transactions on Ecology and the Environment", T. 190, volume 1, pp. 697-706, 2014.

[9] V.F. Kramskoj, Design and bases of calculation of thermal pre-launch preparation digger drive (for example, a bulldozer-ripper DZ-117A). Diss. for a degree of Cand., Voronezh, 1996.

[10] N.N. Karnaukhov, V.V. Konev, A.A. Razuvaev, Y.E. Yurinov, Pat. 2258153, Ros. Federation MPK7 F02N 17/06. Preoperational training system thermal engine and hydraulic drive, publ. 10.08.2005.

[11] I.O. Vashurkin, Thermal preparation of construction machinery in the harsh climate, St. Petersburg.: Nauka, 2005.

[12] V.P. Isachenko, V.A. Osipova, A.S. Sukomel, Heat transfer: textbook 4th edition, Moscow: Energo-edition, 1981. 